\title{
Water Pricing in Central America
}

\section{Colin Palmer}

\section{Introduction}

Rapid urbanisation drastically increases demands for potable water as well as for shelter. Meeting these demands of ten poses severe technical and administrative problems, the latter deriving frequently from the fragmentation of responsibility between different local authorities or water boards. Finance is obviously a major constraint.

Financing the expansion and operation of water supplies poses a number of issues of principle. Because potable water is a basic human need, should it be provided at the expense of the general public through taxation? Or should it be specifically charged to the consumer because not all taxpayers enjoy a public supply, because water may be used for commercial purposes or because its use must be disciplined? If direct charges are to be imposed, how can they differentiate between essential domestic, private luxury and commercial use? Should the charges reflect differences in the actual cost of supply to individual locations? Should some element of redistribution be included in the tariff, the rich paying more and the poor less for comparable consumption? Should charges finance initial capital costs or future expansion as well as current operation? Are tariffs which are fair and adequate also politically enforcable?

These problems have all been reflected in the experience of two Central American States, Costa Rica and El Salvador which the writer visited in 1976.

\section{Water tariff in Costa Rica}

Geographical location and a long distance from water springs have caused San Jose great problems with potable water supply. The first real waterworks were constructed in 1868 , but as the population continued to grow different municipalities were set up, each having its own waterworks. The distribution network extended without any control, leading to a gradual supply deficit which became more serious as 'time passed by since the municipalities lacked resources to improve the system.

Between 1950 and 1960 the supply crisis became so serious in the metropolitan area of San Jose that the government had to intervene in an effort to find a solution. Water production totalled 800 litres per second (lps) against a total demand of $1,345 \mathrm{lps}$, resulting in a 41 per cent supply deficit. In many cases even this water provision was not completely potable. The average cost of water to the public was only US $\$ 0.78$ per month although it can be said that until a national body was formed in 1961 no technical tariff structure existed. In many cases the revenue did not even cover the wages of a plumber. Likewise, payment was not strictly enforced, giving rise to the accumulation of large outstanding debts.

To improve water production a National Water Supply and Sewage Service was set up in 1961. It was decreed that this national body would set up its own tariffs in such manner that there should always be sufficient funds to cover (a) the cost of maintaining, repairing and operating all water supply and sewage systems and (b) interest payments on debts outstanding together with a percentage for capitalisation and development.

The national body determined five classes of consumers in developing the tariff: domestic, ordinary (including commercial users), reproductive (using water as a direct means of commercial profit), preferential (welfare, education, hospitals, etc.) and government. A different tariff was imposed on each class based on capacity for payment and related to consumption volume. Communities were classified in four types in accordance with their overall economic means and at the same time the country was divided into six administrative zones demarcated by various characteristics, amongst them payment capacity.

To established the basic minimum consumption, the necessary amount of water for the primary, essential needs of a big family was determined and a price fixed within minimum income payment capacity. Above this quantity, the unit price of water increased by progressively larger amounts. This has been applied to each type of community: rural, semi-urban, urban and metropolitan in each of the six zones. It was understood that some consumer classes did not exist in some types of community (principally rural and semi-urban), requiring special tariffs for these needs.

Thus within the same community and class, those who consumed more paid a greater unit price than those who consumed less, so that one group made 


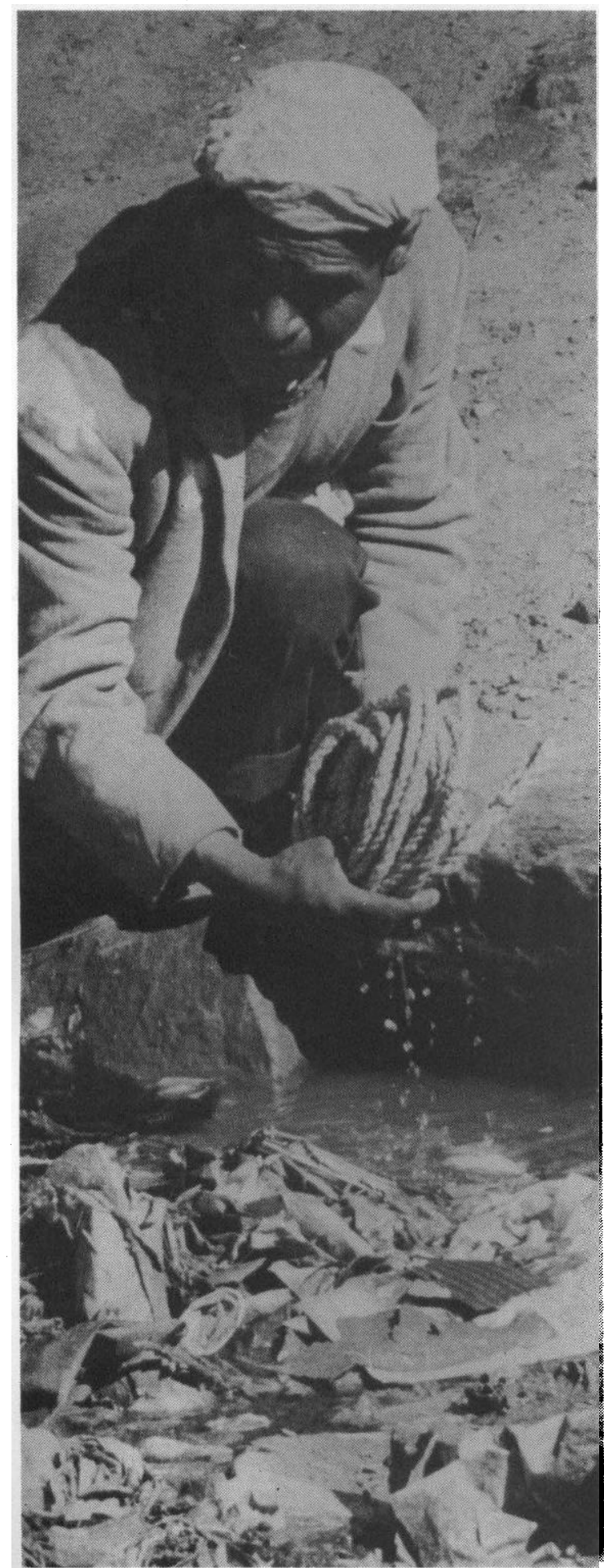

Photo: John Moss; copyright: USPG/MMs̀ Man washing among offal. a contribution to the other. In the same manner, each class had a different tariff in accordance with its own economic situation, and each community and each zone as a whole were charged according to their relative payment capacity. The whole tariff was calculated to cover the true cost of operation and administration so that income would maintain the system and make adequate funds available for further developments.

The tariff was introduced in modified form in 1976. Implementation has been progressing despite considerable social resistance.

\section{Water tariff in El Salvador}

Ever since the colonial period, El Salvador's water supply and sewage functions had been the responsibility of the municipalities. Charges for these services were based on the tariffs of the Municipal Boards which contained the scale charges for water supply and sewerage. The tariffs had no scientific or philosophical basis, and related neither to the costs of providing various levels of service, nor to the recovery of total costs.

The provision of water supply and sewerage services by the municipalities, and the corresponding charges through the municipal rates created considerable confusion. This impeded the development of plans to exploit the country's scarce water resources to the fullest extent, to the benefit of the greatest number of people and at the lowest cost. Underlying the confusion were several factors:

- The granting of direct subsidies by the Central Government for the planning, design and construction of short term water supply and sewerage installations;

- The maintenance of indirect subsidies by the Ministry of Public Works or its departments, such as the General Directorate of Town Planning and Architecture or the General Directorate of Hydraulic Works; these subsidies took the form of direct operation, repair and maintenance of water supply and sewerage installations;

-The increasing water consumption of schools, hospitals, courts, tenements, etc. These properties were not metered, and the state did not make any direct payment for services;

-The deep-rooted custom of paying minimal rates for water supply and nothing for sewerage;

-A conceptual confusion between rates of charges for services and taxation. In this connection, it 
should be noted that the system operated as follows: a group of users of the water supply service paid a low charge for the service it received and then, in addition, paid taxes to the State to enable the latter to subsidise the municipalities according to arbitrary scales entirely unrelated to the amount of water supplied;

-The costs were not recovered and no reserves were built up; there was no provision for replacements; long term plans could not be carried out without incurring heavy loans; the income from provision of the water supply service was insufficient to make the municipalities subjects for loans in the eyes of the national and international organisations.

In 1964 the National Administration for Water and Sewerage (ANDA) in conjunction with the Ministry of Economy began to study the format of a new tariff system that could be applied to the water and sewerage service, which it provided to the community. For a few months in 1968 ANDA operated a scale of charges, which, though increasing its income appreciably, gave its many opponents the opportunity for hostile criticism.

Some of the criticisms directed against the 1968 scale of charges were on purely numerical grounds. Most however concerned the underlying concepts, especially the fact that it was based on consumers' capacity to pay, simulating a taxation system rather than a scale charge for a service provided.

The 1968 scale of charges was consequently abandoned, even though adjustments were made to reduce the administrative charges to the minimum. ANDA continued to cover its debit balances by means of subsidies while seeking a satisfactory formula to marry the interests of the state, which had conceived it as a self-sufficient entity, with those of the consumers, who had indicated that they were prepared to pay the cost of their private consumption, and also with those of ANDA itself, which aimed at providing the best possible service to the public at large, in accordance with its constitution.

ANDA proceeded with a major sample survey to establish the number of water services installed and also the quantity of water consumed in the country. Nine representative 'type' towns were selected, from the 150 towns and communities supplied by ANDA at the time of the study. The number of inhabitants, the system of water supply (gravity or pumping) and the degree of development of the town were taken into account in choosing the 'type' towns. Data were collected on consumptions in households, hotels, commercial and industrial premises, and government offices. Details of the diameters of the connecting piping were also recorded. By projecting the result of this survey, ANDA calculated that it was providing water to 88,848 installations, with an average two-monthly consumption of $8,720,900$ cubic metres in 1969, which was taken as the base year for the investigation.

Since, for climatic reasons, the majority of the population of El Salvador lives in the valleys and plateaux in the mountain region running the length of the country, the water service is to a large extent provided by a pumping system which, combined with the limitation on the water resources, leads to rising cost as the volume required increases. In this situation, ANDA felt that minimum quantities of water should be ensured for family groups and that waste must be avoided. In view of this, the following design criteria were drawn up for the scale of charges for water supply:

- There should be adequate allocations for consumption, based on a minimum quantity per connection of 30 cubic metres per two months, then continuing with allocations of $30-50,50-80$ and $80-120$, which are the quantities taken by average users in each significant group of the population; after this there would be allocations of larger quantities, up to industrial limits of 1,000 cubic metres or more;

- There should be increasing differential charges per cubic metre, for each block of consumption, up to a certain level, beyond which the water would be paid for at a constant unit price.

The criteria justifying the increasing differential tariff system were the cost of production of the water, which increases as the demand increases (contrary to the normal industrial practice of decreasing unit costs), and the limitation on the hydraulic resources which imposes the need for rational use with restrictions based on the elasticity of demand implied by the differentials in the price.

The only variants taken into account for the purpose of establishing the scale charges for water supplies were the quantity of water consumed and the way in which the water was supplied to the community. The distance between the locality and the supply source determined the percentage variation from the basic scale and did not affect the structure of the scale itself. Variations connected with the valuations of the buildings, the category of the users and the activities which the latter pursued were ignored. 
On the basis of its sample survey and of the criteria just described ANDA introduced new tariffs in 1976. The charges for certain blocks of consumption were higher than those attempted in 1968 or subsequently in force. These increases were intended to cover the full current running costs of the service, to replace the previous central government subsidies and to cover rising costs anticipated over the following ten years.

Scale charges have also been extended to the sewerage service which had previously been provided without specific charge in all but two municipalities. A basic scale has been laid down, with variations for each community depending on whether the wastes are conveyed by gravity or by pumping, and whether they are disposed of by exidation reservoirs or treatment plants. The rate of charge within the scale varies with the potable water consumption of the property, and is calculated on the cubic meterage billed.

\section{Conclusion}

This brief summary reveals interesting comparisons and contrasts between two neighbouring countries. Both have sought to impose a national pricing policy to overcome serious deficiencies in water supply provision arising from inadequate recovery of costs and fragmented responsibility. Both have sought to recover developmental as well as running costs from the consumers. Both have introduced differential tariffs which impose a basic charge for a minimum level of essential family supply, but increasing unit costs as consumption rises above this volume.

There are also marked differences in approach. El Salvador passes variations in the cost of supplying individual localities directly to the consumers concerned; Costa Rica seeks to moderate these differences. Costa Rica differentiates between types of water use and between the payment capacities of classes and communities; these variations have been largely ignored in El Salvador.

The Costa Rican experiments have shown a greater and more detailed regard for social equity. However, this does involve charging some people such as commercial consumers or those living in the more cheaply serviced areas, more than the actual costs of their own supply. ANDA's experience shows that the success of such a policy depends upon the extent of political will to overcome the opposition of such consumers to what they might regard as an unduly onerous tariff. 